\title{
APPLICATION OF A DAMAGE STATE METHOD BASED ON PERIOD ELONGATION FOR TIME VARIANT VULNERABILITY OF DEGRADING REINFORCED CONCRETE BUILDINGS
}

\author{
Konstantinos Trevlopoulos ${ }^{1}$, Philippe Guéguen ${ }^{1}$ \\ ${ }^{1}$ ISTerre : Institut des Sciences de la Terre \\ BP 53, 38041 Grenoble CEDEX 9, France \\ konstantinos.trevlopoulos@ujf-grenoble.fr \\ philippe.gueguen@ujf-grenoble.fr
}

Keywords: seismic vulnerability, time variation, aftershock sequence, reinforced concrete, structural degradation

\begin{abstract}
We present a method for a probabilistic estimation of the time variation during aftershock sequences of the vulnerability of reinforced concrete structures which deteriorate as they accumulate damage and become more vulnerable. First we describe the steps of the proposed method and then we apply it in the case of two building models and two aftershock sequences. The degradation of the structural elements of the buildings is assumed to be stochastic and computed with time-history analyses using a hysteretic model of bending response. Then the engineering demand parameter of maximum drift is associated with the elongation of the fundamental period of the structure and we define limit damage states using as thresholds values of the period elongation ratio. The numerical models of the buildings that correspond to the defined damage states are defined and analyzed, in order to calculate their fragility curves and the probability of the damaged building models transitioning to higher damage states. The cumulative probability of exceeding a damage state for the selected aftershock sequences is calculated with a Markov chain whose transition matrices are a function of the intensity of the aftershocks. This results to the variation of the probability of exceedance of period elongation thresholds due to damage accumulation as a function of time during the selected aftershock sequences.
\end{abstract}




\section{INTRODUCTION}

Earthquakes is a principal cause of degradation of the properties of structural elements in reinforced concrete buildings. Stiffness degradation is one of the reasons modern seismic codes such as the Eurocode 8 [1] demand the stiffness of structural elements to be taken into account with its effective value, which equals a portion of the stiffness of the geometric section of each member. Apart from stiffness degradation an increase of the damping ratio of the building may accompany seismic damage and affect its vulnerability [2]. Another source of structural degradation is the non-seismic progressive natural deterioration of the structural materials. Pitilakis et al. [3] estimated the detrimental effect of reinforced concrete steel corrosion with time-dependent fragility curves of multistory buildings. Sanchez-Silva et al. [4] proposed a stochastic model that takes into account the effect of gradual non-seismic deterioration of structural materials along with the structural deterioration due to sudden events such as earthquakes and highlighted the importance of both modes of deterioration.

Iervolino et al. [5] focused on earthquake clusters (aftershock sequences) and developed a probabilistic damage accumulation model for elastic-perfectly plastic single-degree-of-freedom (SDOF) structures and estimated the failure probability as an increasing function of time. Repeated earthquakes and the subsequent damage accumulation may lead to an increased inelastic displacement demand of SDOF systems and an increased ratio of the inelastic displacement to the maximum displacement of the elastic system [6]. Apart from displacement demands, strength demands may also be $20 \%$ averagely higher for degrading SDOF structures in comparison to non-degrading structures, if their period is shorter than the predominant period of the excitation [7] and their ductility demand may be higher, if excited with soft soil seismic records.

One way of quantifying the structural degradation of a building is through the elongation of its fundamental period. The degree of cracking in reinforced concrete elements because of static loads as well as the cracking of infill walls during the earthquake are considered to contribute significantly to the elongation of the natural period of buildings [8]. Katsanos et al. [9] estimated the period elongation for the design earthquake and twice the design earthquake at approximately 1.2 and 1.7 on average in the case of moment resisting frames and dual structural system multi-storey buildings designed with Eurocode 8. Only in extreme cases of severely degrading buildings a ratio of 2.0 was estimated. Katsanos and Sextos [10] also proposed an empirical function for period elongation based on the structural period and the force-reduction factor. Moreover, they showed that PGA has a low correlation with the predominant inelastic period in contrast to spectral acceleration. Based on measurements in damaged buildings after the 2011 Lorca earthquake Vidal et al. [11] proposed relationships for the period of the damaged buildings as a function of the number of stories. According to these relationships the period elongation corresponding to EMS-98 [12] damage grade 1, 2 and 3-4 is equal to $20 \%, 43 \%$ and $65 \%$ and is independent of the number of storeys. The period elongation ratio has been observed to be in an analogy to the stiffness and the force-reduction factor (ratio of the maximum seismic force to yield force) of SDOF oscillators [10] while the effect of earthquake magnitude, distance and soil conditions has been estimated to be of minor significance.

Given that reinforced concrete buildings may accumulate damage during aftershock sequences and become more vulnerable we deem necessary the development of a model of timevariable vulnerability for the aftershock time-period. This is the aim of this paper and we consider the variation of the vulnerability over these time-periods a significant piece of information for buildings part of critical infrastructures such as the Port of Thessaloniki, whose location we use in one case study. In many cases the structural health of such buildings is monitored with proper instrumentation and since structural degradation can be observed and localized through eigenfrequency variation $[13,14]$ we are employing limit damage-state thresholds in terms of 
the ratio of the periods of the elastic and the degraded building $\left(\mathrm{T}_{\mathrm{in}} / \mathrm{T}_{\mathrm{el}}\right)$ for developing an operative tool in emergency situation. The properties of the structural elements of the degraded building models are computed based on the stochastic inelastic deformations calculated with finite element time-history analyses of the original building with excitations covering a wide intensity range. Using the derived fragility curves the cumulative probability of exceedance of period elongation thresholds is then calculated for the cases of two real aftershock sequences.

\section{SELECTED BUILDING MODELS}

For the application of the developed method for time-varying vulnerability two reference mid-rise building models [15] are selected (Figure 1, Table 1). The first is a high-code reinforced concrete moment resisting frame designed with the Greek seismic code of 2001 (EAK 2000) [16] and the second building is a low-code building with a shear wall system, i.e. a structural system with shear walls carrying more than $65 \%$ of the base seismic shear force [17], designed with the first seismic code that came into effect in Greece in 1959. The provisions of the 2001 code bear similarities to EN 1998-1 [17] and demand capacity design with structural member detailing for ductile behavior aiming for energy dissipation in the seismic resisting system and plastic building collapse mechanisms. According to a 2001 survey $32 \%$ of the building stock of Greece predated the 1959 code, $46 \%$ was constructed between 1959 and 1985, when a new seismic code was introduced [18], under which $22 \%$ of the stock was built. Based on more recent data in the city of Grevena in Greece the reinforced concrete buildings built after 1959, 1985 and 2001 consist respectively $49 \%, 11 \%$, and $19 \%$ of the stock [19]. The selected models fall under the C1M and C2M model building types of HAZUS [20] and will be thus referred to for brevity.

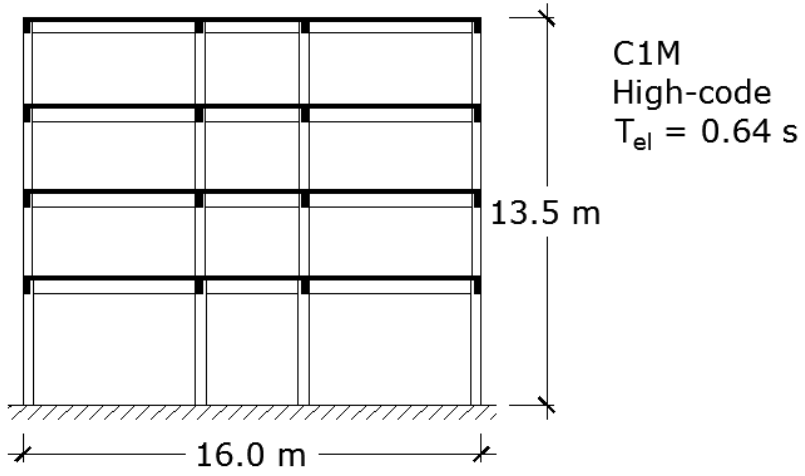

$\mathrm{C} 2 \mathrm{M}$

Low-code

$\mathrm{T}_{\mathrm{el}}=0.38 \mathrm{~s}$

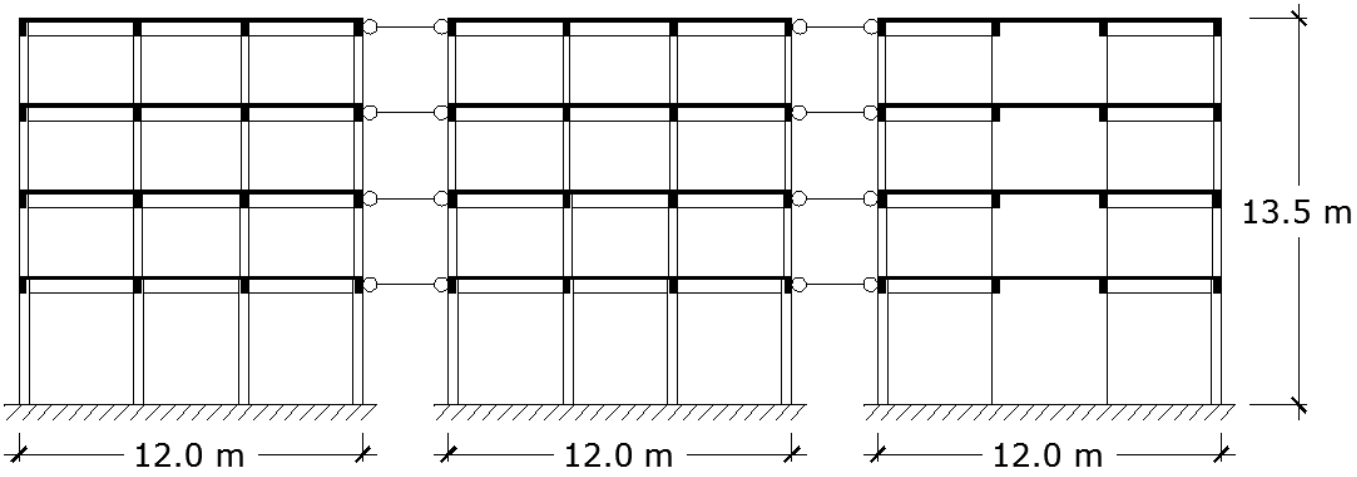

Figure 1: Reference building models: C1M high-code moment resisting frame, C2M low-code coupled shear wall and moment resisting frames. 


\begin{tabular}{lllllll}
\hline Type & Structural System & Code & Concrete & Steel & Mass $(\mathrm{t})$ & $\mathrm{T}_{\mathrm{el}}(\mathrm{s})$ \\
\hline C1M & Moment resisting frame & High & C20 & S400 & 130.0 & 0.64 \\
C2M & Shear walls & Low & B225 & StI & 491.9 & 0.38 \\
\hline
\end{tabular}

Table 1: Details of the selected building models.

Three types of analyses are performed with OpenSees [21]; fiber, non-linear time-history and modal. The fiber analyses are employed to calculate the yield moment and curvature of each structural element through a bi-linear approximation of the numerical results. This data is then used to model the inelastic response of the elements with a distributed plasticity model of hysteretic response. Pinching in the moment-curvature loops is used only for the structural walls with a factor of 0.3 assuming a strong pinching effect. The modal analyses are used to calculate the fundamental period of the models in their undamaged and structurally degraded states. In the total mass of each model the mass corresponding to structural elements infill walls, live and dead loads of the slab floors are included. According to the code for interventions in existing buildings in Greece [22] the bending stiffness (EI) of structural elements should be reduced to the value of the modulus at yield, which is averagely $25 \%$ or less of the stiffness of the geometric uncracked section $\left(\mathrm{EI}_{\mathrm{g}}\right)$ [17]. It is assumed that this is intended for pushover analysis with elastic-perfectly plastic springs. Since a hysteretic law is used for bending behavior in the context of dynamic analyses, which models stiffness degradation after yield, the reduced elastic stiffness of the concrete elements is required to account for Stage II cracking. In the C2M model the stiffness is taken equal to $40 \%, 60 \%$ and $80 \%$ of the geometric stiffness for beams, perimeter columns and shear walls, and inner columns respectively according to the comments of EAK 2000. This leads to bending stiffness of the elements in agreement with the momentcurvature results from the fiber analyses at the range of small elastic deformations (Figure 2) and to a more effective estimation of the elastic fundamental period of the building $\left(\mathrm{T}_{\mathrm{el}}\right)$.

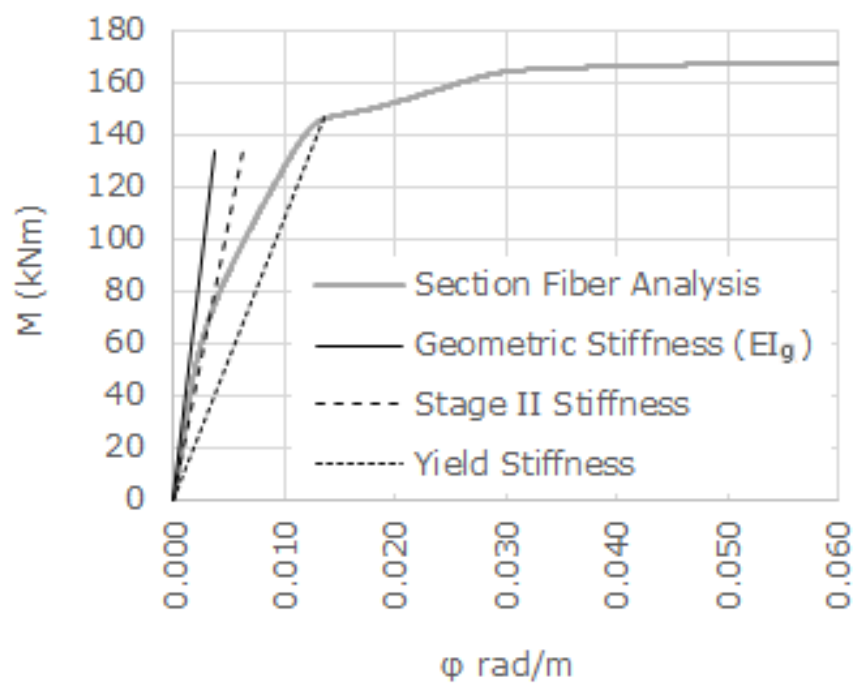

Figure 2: Moment-curvature results at the foot of the perimetric columns of the C1M building compared to the geometric, Stage II and yield stiffness of the section.

\section{METHOD DESCRIPTION}

The assessment of the variation of the vulnerability of the studied buildings during an aftershock sequence is performed by following steps 1-7: 
1. For each seismic event (Magnitude/Distance couple) in the sequence ( $i=1-n)$ compute the corresponding Intensity Measure $\left(\mathrm{a}_{\mathrm{i}}\right)$, e.g. PGA, with a suitable Ground Motion Prediction Equation either from [23] or [24] for Europe.

2. Calculate the fragility curves of the undamaged building prior to the main shock for each damage state as a function of the selected Intensity Measure(s).

3. Define the damage states of the building in terms of period elongation due to structural degradation $\left(\mathrm{T}_{\mathrm{in}} / \mathrm{T}_{\mathrm{el}}\right.$ or $\left.\Delta \mathrm{T}=\left(\mathrm{T}_{\mathrm{in}}-\mathrm{T}_{\mathrm{el}}\right) / \mathrm{T}_{\mathrm{el}}\right)$. Calculate the degraded stiffness of the structural elements of the building in each damage state in order to model the building in each state. This step is described analytically in Paragraph 4.

4. For each of the considered damage states $\left(\mathrm{DS}_{\mathrm{j}}, \mathrm{j}=1-\mathrm{m}\right)$ of the building calculate the fragility curves for every higher damage state.

5. Form the vector of the probabilities of exceedance of each damage state (e.g. Table 2 for four DSs) in terms of drift and frequency reduction at the time of the first seismic event $\left(\mathrm{t}_{1}\right)$ and its corresponding IM value $\left(\mathrm{a}_{1}\right)$ from the computed fragility curves of the undamaged building (Equation 1).

$$
\begin{aligned}
& P_{(t 1), j}=P\left[D S_{(t 1)} \geq j \mid I M_{(t 1)}=a_{1}\right], \quad j=1-m \\
& \begin{array}{llll}
\hline \mathrm{P}_{(\mathrm{t} 1), 01} & \mathrm{P}_{(\mathrm{t} 1), 02} & \ldots & \mathrm{P}_{(\mathrm{t} 1), 0 \mathrm{~m}} \\
\hline
\end{array}
\end{aligned}
$$

Table 2: Vector of probabilities of exceedance of damage states at the time of the main shock $\left(\mathrm{t}_{1}\right)$.

6. Calculate the probability of exceedance of each damage state for the IM values $\left(a_{i}\right)$ that correspond to the events in the catalog (catalog to be defined) from the computed fragility curves (Equation 2) of the building in all considered damaged states $(1-\mathrm{m})$. These values are then used to form the damage state transition matrices for each seismic event as shown in Table 3.

$$
P_{(t \mathrm{i}), j}=P\left[D S_{(t \mathrm{i})} \geq j \mid D S_{(t \mathrm{i})} \geq k, I M_{(t \mathrm{i})}=a_{\mathrm{i}}\right], \mathrm{k} \leq j=1-m
$$

\begin{tabular}{llllll}
\hline & $\mathrm{DS}_{(\mathrm{ti})} \geq 0$ & $\mathrm{DS}_{(\mathrm{ti})} \geq 1$ & $\mathrm{DS}_{(\mathrm{ti})} \geq 2$ & $\ldots$ & $\mathrm{DS}_{(\mathrm{ti})} \geq \mathrm{m}$ \\
\hline $\mathrm{DS}_{(\mathrm{ti}-1)}=0$ & 1.0 & $\mathrm{P}_{(\mathrm{t}), 01}$ & $\mathrm{P}_{(\mathrm{ti}), 02}$ & $\ldots$ & $\mathrm{P}_{(\mathrm{i}), 0 \mathrm{~m}}$ \\
$\mathrm{DS}_{(\mathrm{ti}-1)}=1$ & 0.0 & 1.0 & $\mathrm{P}_{(\mathrm{ti}), 12}$ & $\ldots$ & $\mathrm{P}_{(\mathrm{ti}), 1 \mathrm{~m}}$ \\
$\mathrm{DS}_{(\mathrm{ti}-1)}=2$ & 0.0 & 0.0 & 1.0 & & $\mathrm{P}_{(\mathrm{ti}), 2 \mathrm{~m}}$ \\
$\ldots$ & $\ldots$ & $\ldots$ & & $\ldots$ & $\ldots$ \\
$\mathrm{DS}_{(\mathrm{ti}-1)}=\mathrm{m}$ & 0.0 & 0.0 & 0.0 & $\ldots$ & 1.0 \\
\hline
\end{tabular}

Table 3: Transition matrix $\left(\mathrm{T}_{\mathrm{r}(\mathrm{ti})}\right)$ consisting of time-variant probabilities of exceedance of a damage at the time of an aftershock $\left(\mathrm{t}_{\mathrm{i}}\right)$ depending on the damage state of the building prior to the event $\left(\mathrm{t}_{\mathrm{i}-1}\right)$.

7. Calculate the probability of the building exceeding a damage state at the time points of the aftershocks with a discrete-time Markov chain with a discrete time space (Equation 3) using the transition matrices. Markov chains are used to describe systems going through a chain of events or states, in which every following state depends only on the current state. Note that the initial state vector in the right hand side has zero values with the exception of its first element which is equal to 1.0. This way the probability of exceedance of the damage states is computed given that the building is at the beginning of 
the calculation in its first state, which here is its original undamaged state. With Equation 3 it is also possible to compute the exceedance probabilities given that the building is in a higher damage state by assigning the 1.0 value to the corresponding element of the vector.

$$
\left[P\left[D S_{t n} \geq 1\right] \ldots P\left[D S_{t n} \geq m\right]\right]=\left[\begin{array}{llll}
1 & 0 & \ldots & 0
\end{array}\right] \prod_{1}^{n} T_{\mathrm{r}(t i)}
$$

\section{PERIOD ELONGATION-BASED DAMAGE STATES}

In this paper the damage states that are used are defined using as thresholds values of the elongation of the period of the building $\left(\mathrm{T}_{\mathrm{in}} / \mathrm{T}_{\mathrm{el}}\right.$ or $\left.\Delta \mathrm{T}\right)$. Limit damage states are typically defined with thresholds of the maximum interstorey drift (e.g. in HAZUS [20]). The advantage of using such thresholds is that, since the elongation of the first eigenperiod of a building can be measured by means of instrumentation immediately after the mainshocks, the degree of the suffered structural damage can be available remotely and in real time without the need for inspection. These limit damage states are defined using the results of the same set of non-linear analyses used for the calculation of the fragility curves of the building in its original state.
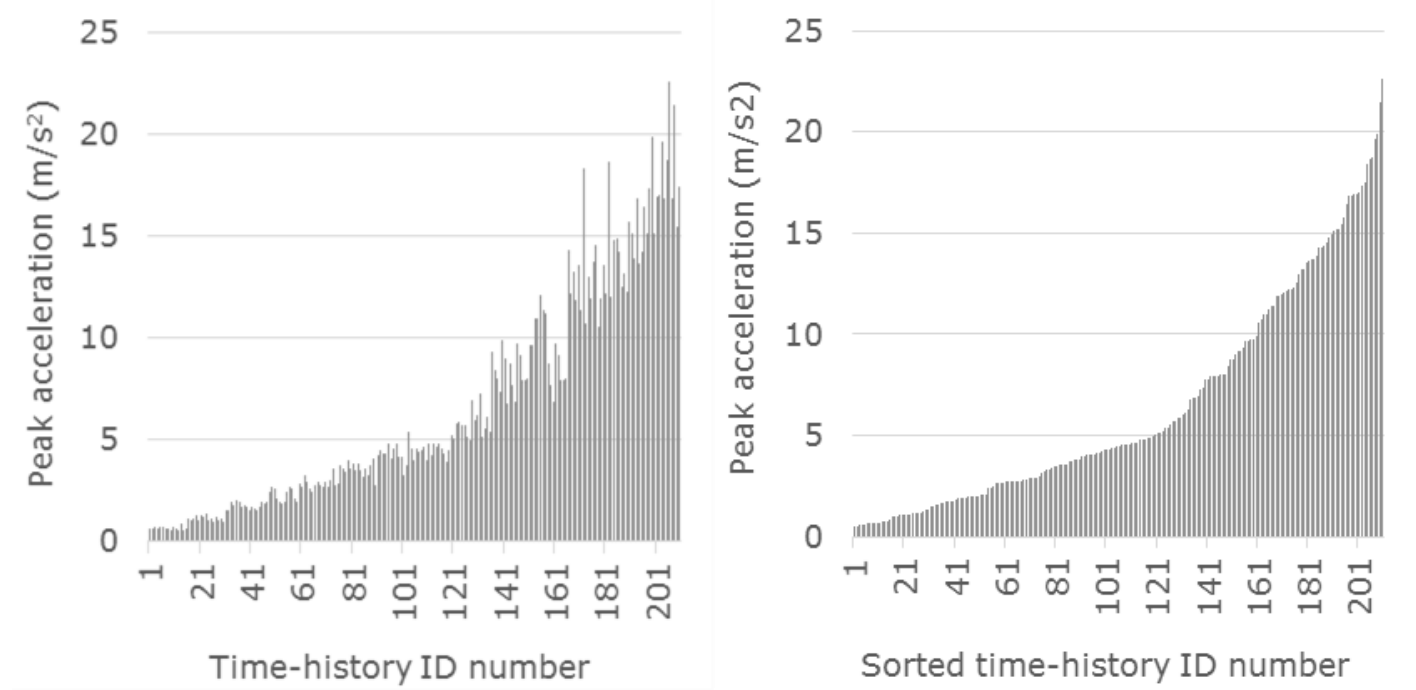

Figure 3: PGAs of the synthetic input motions.

\subsection{Seismic input time-histories}

The time-history analyses are performed assuming full fixity of the foot all vertical structural elements of the ground floor, where the seismic excitation was applied. Fourteen groups of 15 synthetic acceleration time histories are used as base excitation in the time-history analyses. Each group was generated with Eurocode's Type C spectrum as the average target spectrum. The synthetic time-histories were generated with SeismoArtif [25], which implements a method based on Hallodorson and Papageorgiou [26], for the case of a near field source under an interplate regime, with hypocentral distance of $9 \mathrm{~km}$. The PGA of each of the 14 target spectra ranges from $0.005 \mathrm{~m} / \mathrm{s}^{2}$ to $15.0 \mathrm{~m} / \mathrm{s}^{2}$. However individual time histories have a wider range exceeding $20.0 \mathrm{~m} / \mathrm{s}^{2}$ (Figure 3). By using such a set of synthetic accelerograms with a varying intensity it is assured that the frequency content of each accelerogram corresponds to its intensity. Zacharenaki et al. [27] have shown that the response to time-histories with frequency content resulting from scaling in Incremental Dynamic Analysis [28] may be lower than the response to natural and synthetic records in the case of SDOFs with a period lower than $0.50 \mathrm{~s}$, while being unbiased for SDOFs with period higher than $0.70 \mathrm{~s}$. Although for structures with 
multiple degrees of freedom the assessment of this bias may be more complex, we consider the selected time-histories suitable for the $\mathrm{C} 2 \mathrm{M}$ building, as its fundamental period is $0.38 \mathrm{~s}$.

\subsection{Structural degradation and period elongation}

Besides the calculation of the storey drifts for each building from the series of analyses model we calculate the stiffness degradation ratio at selected sections of each structural element (the ratio of the secant modulus $\left(\mathrm{EI}_{\mathrm{sec}}\right)$ of the moment-curvature loops of each section to the elastic $\left(\mathrm{EI}_{\mathrm{el}}\right)$ stiffness of the section) as a function of the first storey drift (Figure 4). HAZUS sets the collapse threshold at a maximum interstorey drift of 0.0333 for $\mathrm{C} 2 \mathrm{M}$ buildings, while Kappos [29] at 0.02 for buildings in Greece. Therefore we calculate the degraded stiffness of each structural element with its corresponding power fit function (excluding values equal to 1.0) for a series of first storey drift in the range of $1 \cdot 10^{-4}$ to $4 \cdot 10^{-2}$ and perform modal analyses of the resulting building models. The ratio of the fundamental period of these building models that have undergone inelastic deformations to the period of the elastic building models in its original undamaged state $\left(\mathrm{T}_{\mathrm{in}} / \mathrm{T}_{\mathrm{el}}\right)$ is shown in Figure 6a. We observe that the period elongation of the $\mathrm{C} 1 \mathrm{M}$ building starts at a higher drift compared to the stiffer $\mathrm{C} 2 \mathrm{M}$ building and that its period elongation is sharper. The ratio of the total drift to the first storey drift -as expected-is significantly higher for the building with the shear walls in comparison to the moment resisting frame building. Using the computed ratio of total to first storey drift (Figure 5) we then plot the period elongation ratio $\mathrm{T}_{\mathrm{in}} / \mathrm{T}_{\mathrm{el}}$ as a function of the total drift (Figure 6b). By defining damage limit state thresholds as period elongation equal to $20 \%, 40 \%$ and $60 \%$ we obtain the corresponding drifts (Table 4). We assume that $\Delta \mathrm{T}=60 \%$ corresponds to a damage state on the verge of collapse based on the observations in Vidal et al. [11]. For these drift values we calculate the stiffness of each element and model the studied buildings in the defined limit damage states.

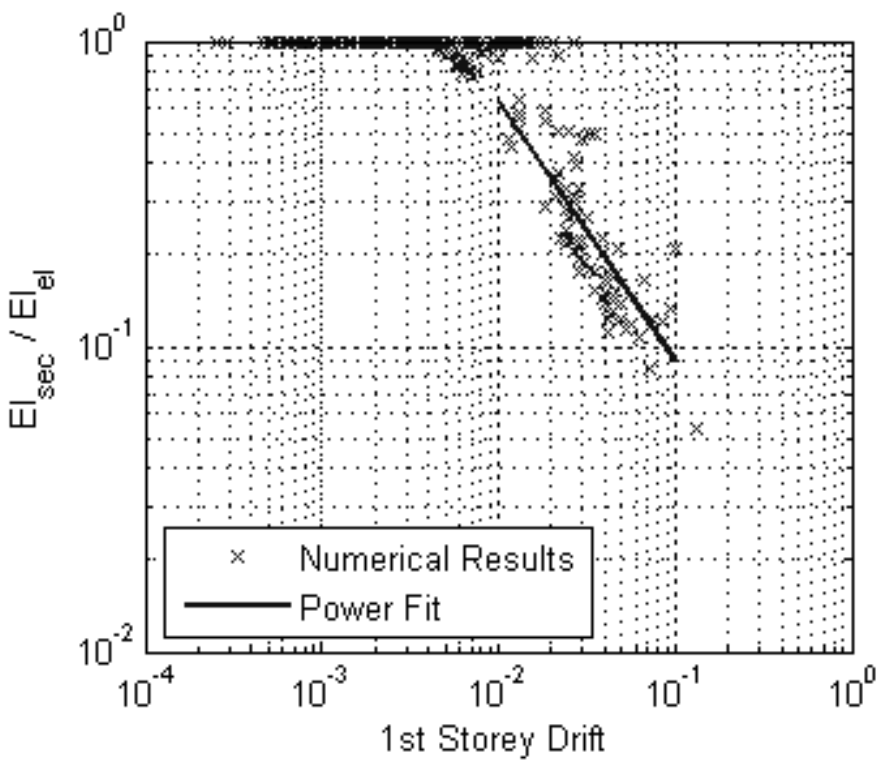

Figure 4: Stiffness degradation ratio at the foot of a corner column; results and power fit. 


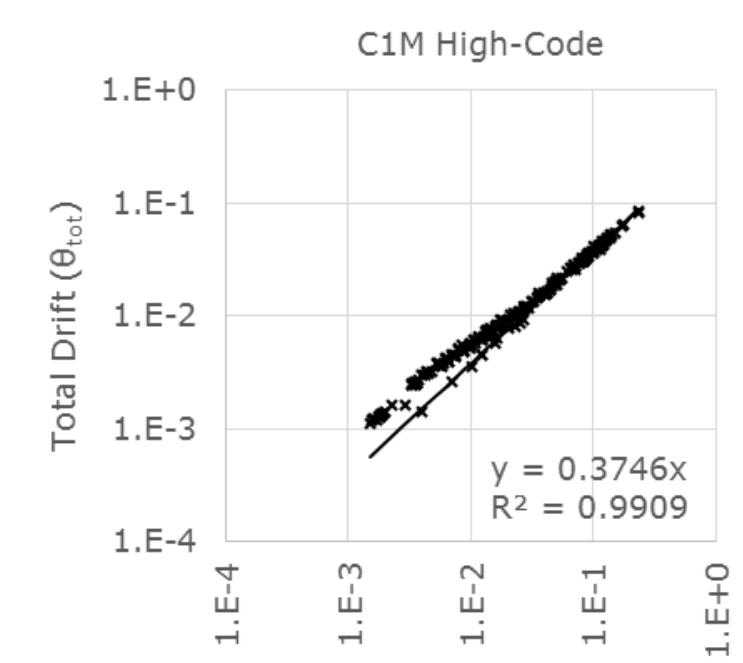

a)

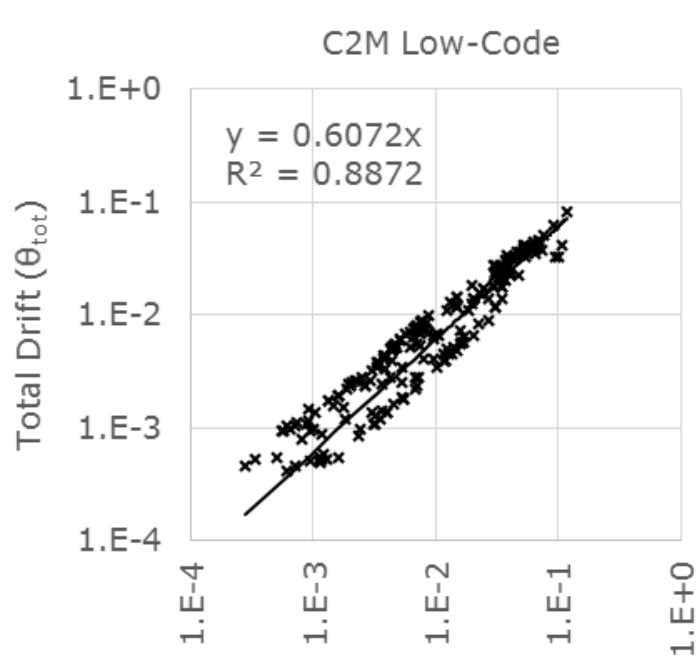

b)

$1^{\text {st }}$ Storey Drift $\left(\theta_{1}\right)$

Figure 5: Total versus $1^{\text {st }}$ storey drift in the case of the studied C1M high code (a) and C2M low code building models.

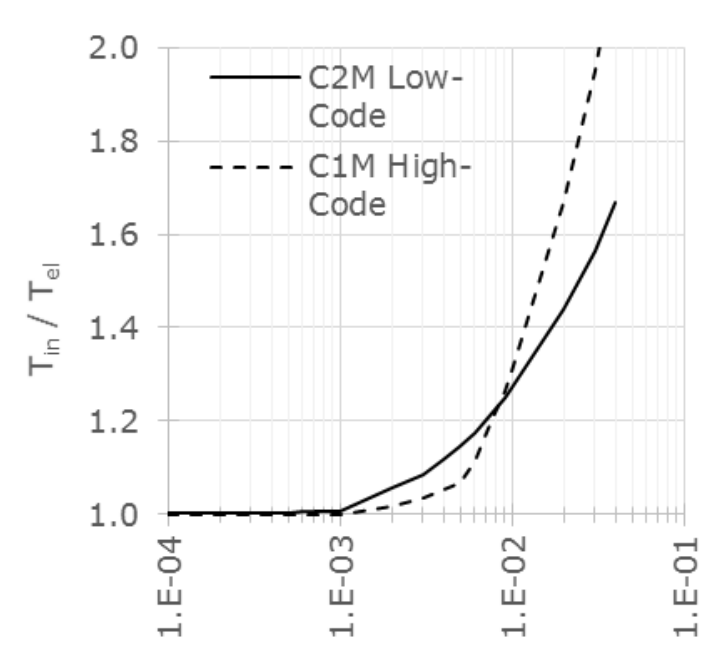

a) $1^{\text {st }}$ Storey Drift

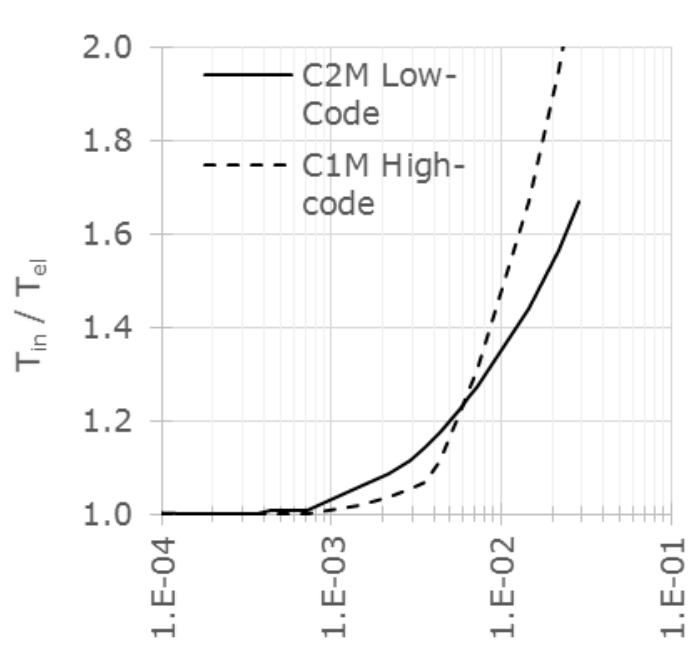

b)

Total Drift

Figure 6: Period elongation ratio $\left(\mathrm{T}_{\mathrm{in}} / \mathrm{T}_{\mathrm{el}}\right)$ as a function of the first storey drift (a) and total drift (b) of the buildings in this study.

\begin{tabular}{cccccccc}
\hline & & \multicolumn{3}{c}{ C2M Low-code } & \multicolumn{3}{c}{ C1M High-code } \\
\hline$\Delta \mathrm{T}(\%)$ & $\mathrm{T}_{\text {in }} / \mathrm{T}_{\mathrm{el}}$ & $\mathrm{T}_{\mathrm{in}}$ & $\theta_{\max }$ & $\theta_{\mathrm{tot}}$ & $\mathrm{T}_{\text {in }}$ & $\theta_{\max }$ & $\theta_{\text {tot }}$ \\
20 & 1.2 & 0.47 & 0.0070 & 0.0042 & 0.769 & 0.0076 & 0.0029 \\
40 & 1.4 & 0.54 & 0.0177 & 0.0107 & 0.898 & 0.0125 & 0.0047 \\
60 & 1.6 & 0.62 & 0.0328 & 0.0199 & 1.026 & 0.0181 & 0.0068 \\
\hline
\end{tabular}

Table 4: Period elongation thresholds and the corresponding inelastic periods and drifts of the two building models. 


\section{TIME-VARYING VULNERABILITY}

\subsection{Structural period elongation-based fragility curves}

Having modeled the studied buildings in the defined period-elongation based damage states we perform inelastic time history analyses with the degraded building models with the same set of excitations described in paragraph 4.1 in order to calculate their fragility curves. Typically fragility curves are plotted in groups corresponding to the probability of each limit state being exceeded given that the building is in its original state. These fragility curves for the selected buildings are presented in Figure 8. The fragility curves of the $\mathrm{C} 1 \mathrm{M}$ building have higher values than the curves of the $\mathrm{C} 2 \mathrm{M}$ building in the considered range of PGAs. Figure 7 shows the numerical results of the first storey drift versus PGA and the corresponding relationships. The scatter of the results is higher in the case of the $\mathrm{C} 2 \mathrm{M}$ model, which can be seen both visually and by comparing the values ( 0.95 versus 0.81$)$ of the coefficient of determination $\left(R^{2}\right)$. A possible explanation for this is the adoption of PGA as an intensity measure [30].
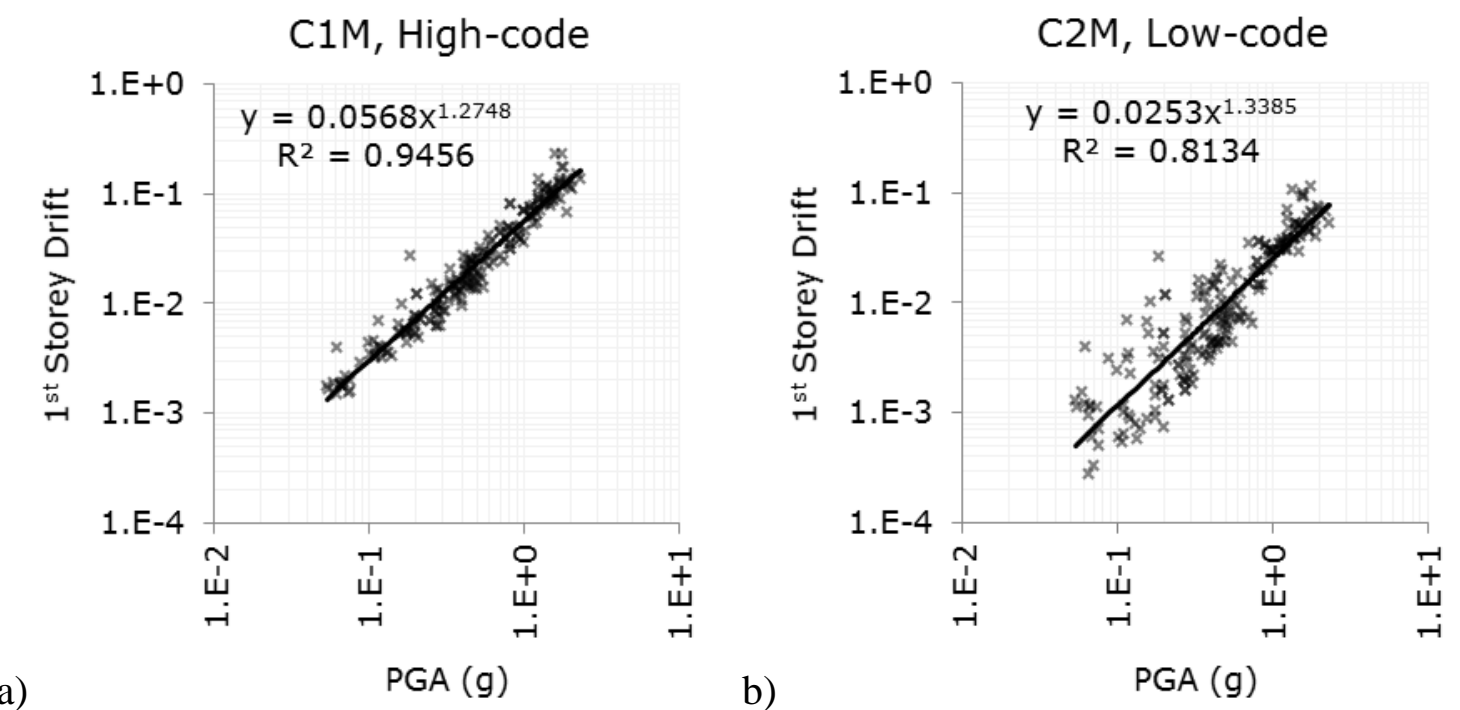

Figure 7: First storey drift versus PGA numerical results for the C1M (a) and C2M (b) buildings.
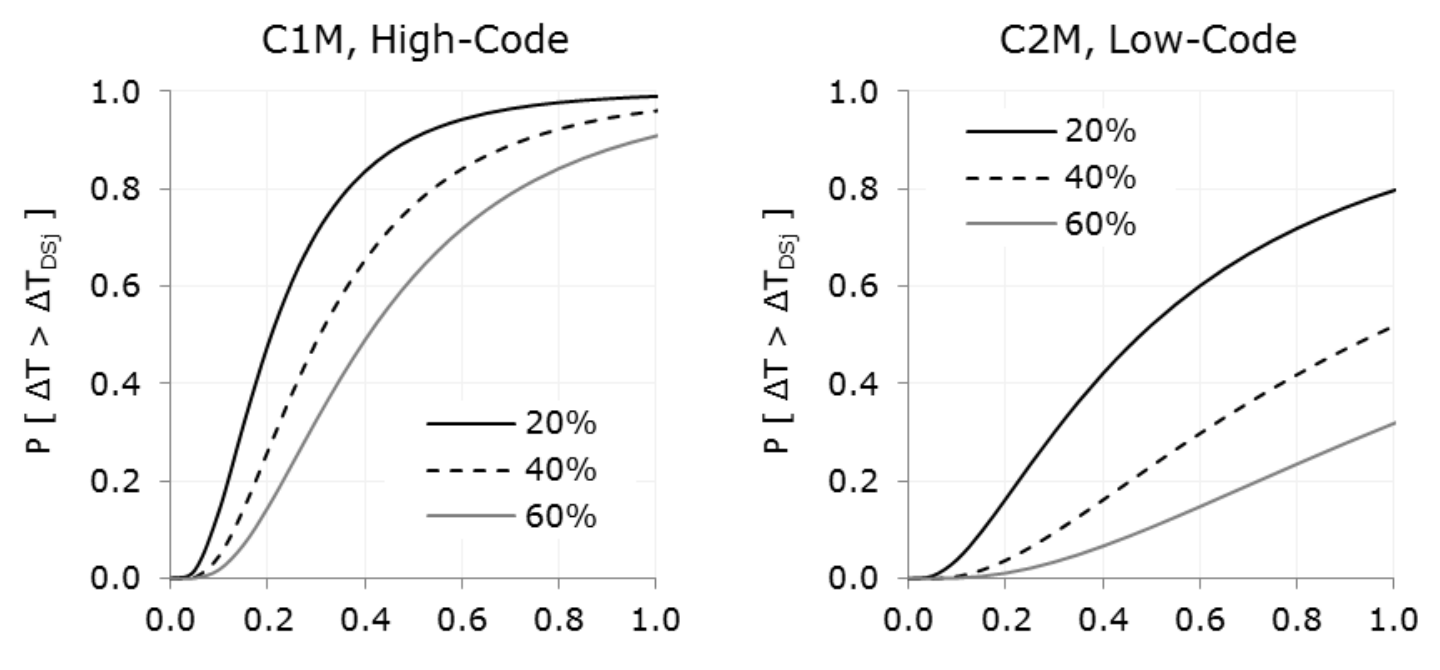

a)

PGA (g)

b)

PGA (g)

Figure 8: Fragility curves of the C1M (a) and C2M (b) buildings based on period elongation thresholds. 
We are proposing an alternative grouping which gives the probability of exceedance of a specific damage state given that the building is in all lower damage states. This way the probability of transition from the current state to a higher damage state is obtained in order to be used in the transition matrices (Paragraph 3). Figure 9 gives the exceedance probabilities of limit damage states with period elongation thresholds of $40 \%$ and $60 \%$ as a function of the PGA given that the building models are in a lower damage state. We observe that the probability of exceedane of $\Delta \mathrm{T}=40 \%$ is higher for the building models in damage state with $\Delta \mathrm{T}=20 \%$ than for the building in its original state $(\Delta \mathrm{T}=0 \%)$ and that the difference is larger in the case of the $\mathrm{C} 2 \mathrm{M}$ low-code building.

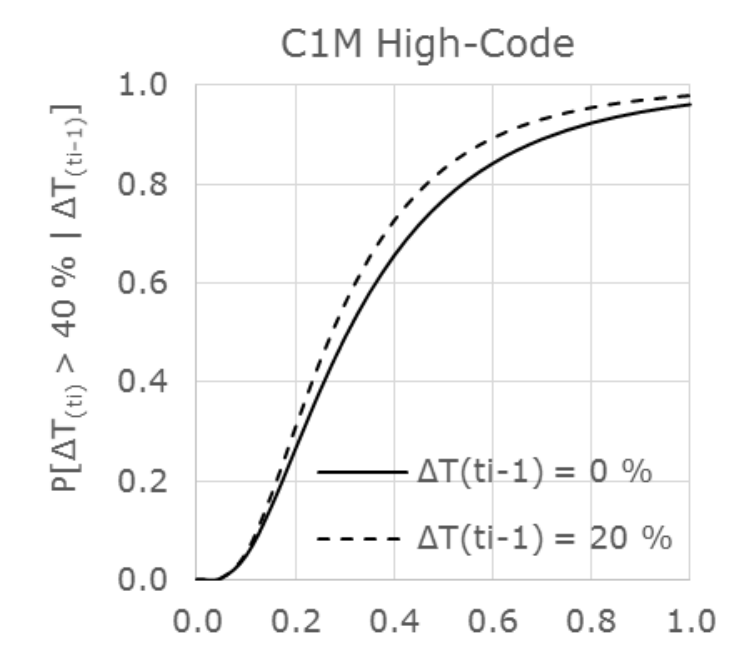

a)

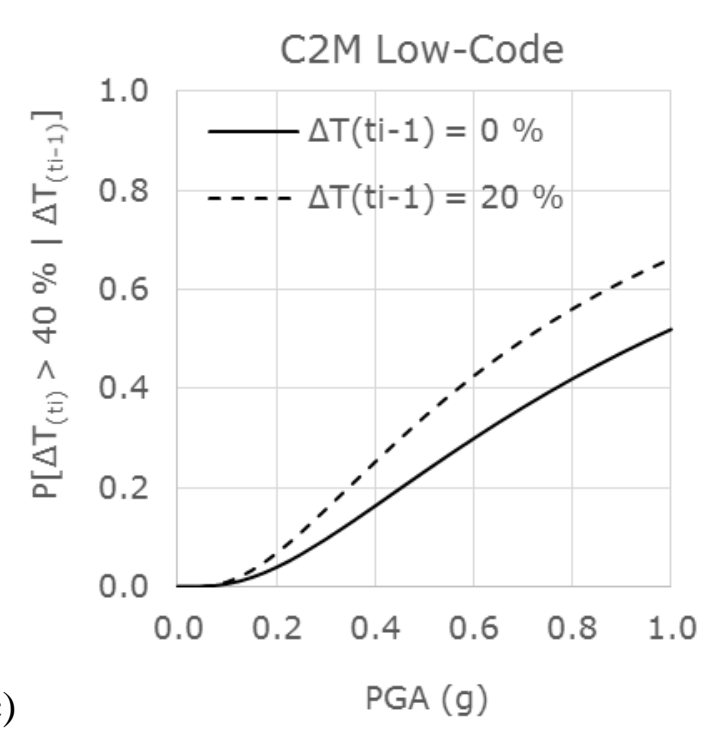

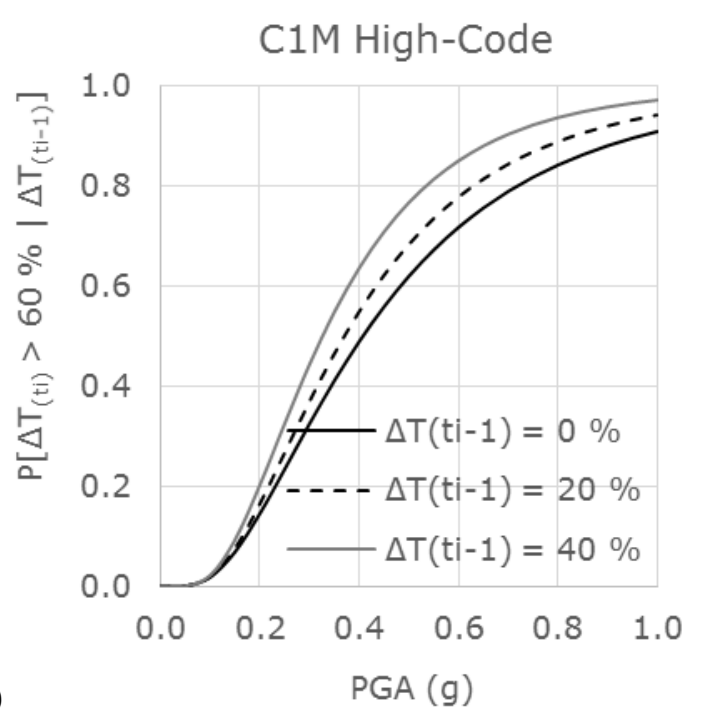

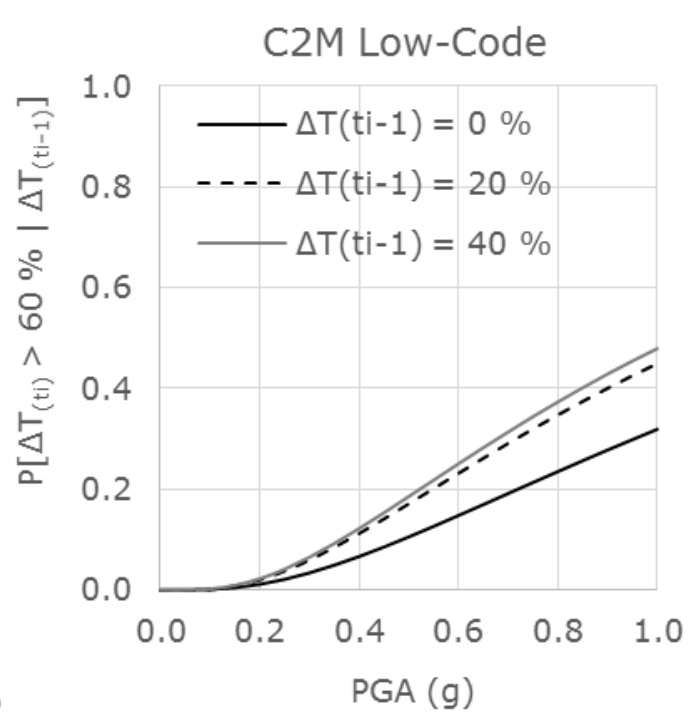

Figure 9: Probability of transition of the studied building models at a time point $\left(\mathrm{t}_{\mathrm{i}}\right)$ from lower damage states to the damage states defined by the period elongation thresholds of $40 \%$ (a, c) and $60 \%$ (b, d). 


\subsection{Probability of exceedance of period elongation thresholds over periods of aftershock sequences}

The probability of exceedance of the three defined threshold of period elongation are computed for the cases of the aftershock sequences of the 1978 Thessaloniki (events with $M \geq 4.3$ [31]) and 1994 Northridge earthquakes [32, 33] considered as case studies. We assume that the studied buildings have the coordinates listed in Table 5 with a main-shock epicentral distance of $28.2 \mathrm{~km}$ and $16.0 \mathrm{~km}$. For the calculations for the 1978 Thessaloniki sequence the building location was selected assuming that the building is part of the critical infrastructure of the port of the city, while for the Northridge case a fictional location is used. In the case of the Thessaloniki sequence the event details from the seismicity catalog $[34,35]$ were used since the listed magnitudes are practically equal to the moment magnitude [36]. The PGA at the base of the building for each seismic event is estimated with the ground motion prediction equation (GMPE) of Akkar and Bommer [37], as it is considered suitable for the tectonic setting of Thessaloniki [24]. The same equation is also used for the case of the Northridge sequence for demonstration

The prediction of ground motion parameters such as the PGA is characterized by significant uncertainty and an elaborate approach is recommended (e.g. logic tree) including other GMPEs (e.g. [38]) and different types of excitation time series [39] for detailed studies. We limit this study to the computed PGAs by the selected GMPE for simplicity, since our aim is the presentation of the proposed method.

Next we form the transition matrices by computing the values of the fragility curves that correspond to the PGAs of the seismic events in the aftershock sequences. The probability of exceedance of the limit damage state thresholds at the time points of the seismic events is then computed as the product given by Equation 3. Figure 10 shows the results of this calculation for the 1978 Thessaloniki aftershock sequence and Figure 11 for the 1994 Northridge sequence. The largest increase of the exceedance probabilities is observed at the time points of the main shocks. In the Northridge case it takes place at the beginning of the aftershock sequence, while in the case of Thessaloniki on day 43. In both cases the C1M building has a higher probability of sustaining damage in comparison to the $\mathrm{C} 2 \mathrm{M}$ building although it's a high-code building and the $\mathrm{C} 2 \mathrm{M}$ is low-code.

\begin{tabular}{lccc}
\hline Case & $\lambda$ & $\varphi$ & $\mathrm{R}(\mathrm{km})$ \\
\hline Thessaloniki 1978 & $40.634 \mathrm{~N}$ & $22.937 \mathrm{E}$ & 28.2 \\
Northridge 1994 & $34.194 \mathrm{~N}$ & $-118.376 \mathrm{~W}$ & 16.0 \\
\hline
\end{tabular}

Table 5: Fictional coordinates of the studied buildings for the two case studies and the main shock epicentral distance.

\section{CONCLUSIONS}

Our main goal was to present a method that calculates the variation of the vulnerability of reinforced concrete structures during aftershock sequences. The proposed method and the numerical results show that reinforced concrete buildings indeed may become more vulnerable due to damage accumulation during aftershock sequences. It is shown that the probability increase due to the main shock is the largest in the presented case studies, but it is only a fraction of the cumulative probability of exceedance of a damage state throughout the aftershock sequences. The probability of damage state exceedance in the numerical results for the case studies of the aftershock sequences of the Thessaloniki (1978) and the Northridge (1994) follows a similar trend to the failure probability during the aftershock sequence period as estimated by Iervolino et al. [5]. Moreover, the assumption that period elongation of $\Delta \mathrm{T}=60 \%$ corresponds 
to a state near collapse is in agreement with the empirical estimations by Katsanos and Sextos [10].

This study makes the hypothesis that the response of plane numerical models is representative of the response of the actual three-dimensional buildings, however this is a common hypothesis in seismic vulnerability studies and it reduces the computational load. We also ignore the variation of the damping of the structure as it accumulates seismic damage and the degradation of strength of the structural elements. Furthermore, the sensitivity of the numerical results on the type of input time-histories is not investigated.

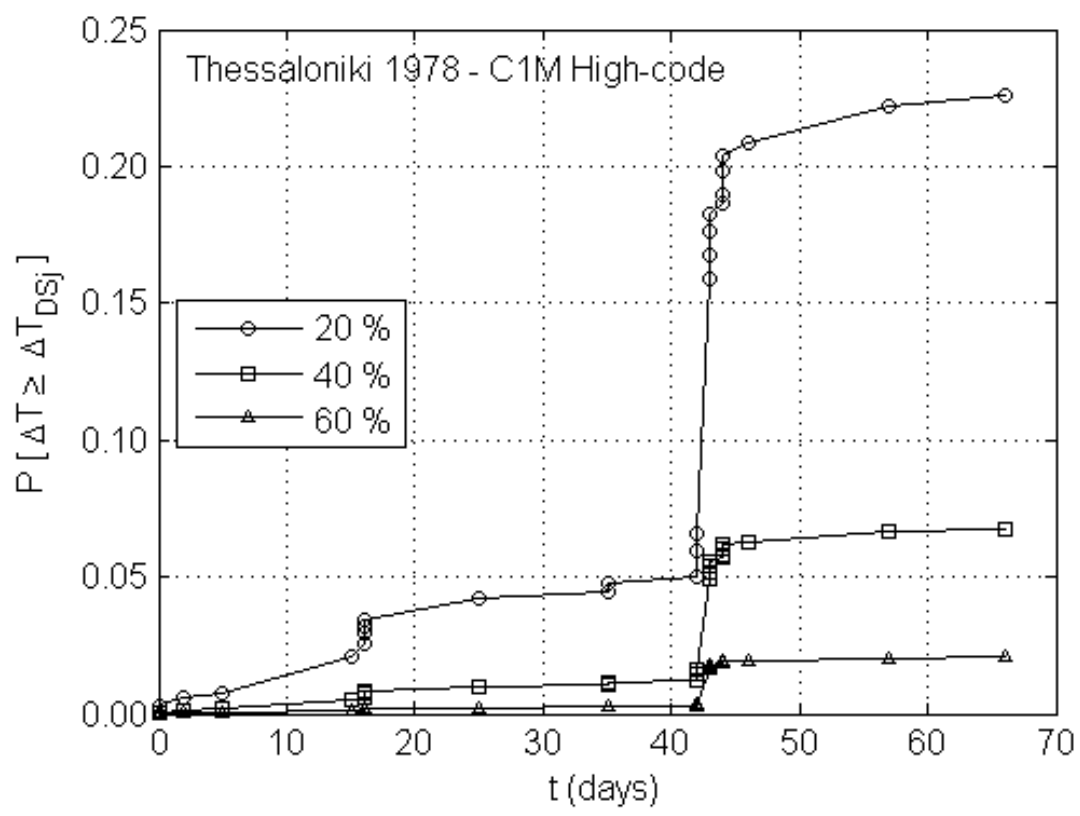

a)

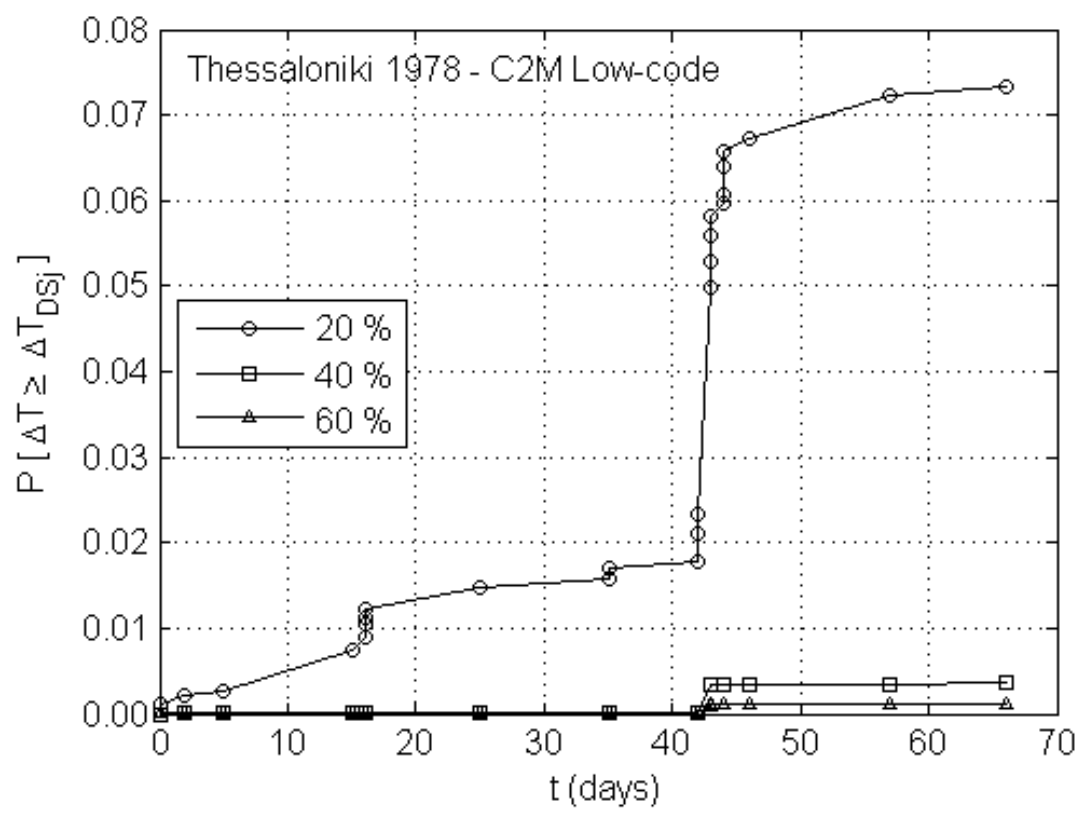

Figure 10: Probability exceedance of limit damage state thresholds in the form of period elongation $(\Delta \mathrm{T})$ in the case of the 1978 Thessaloniki aftershock sequence for the C1M high-code (a) and the C2M low-code building (b). 


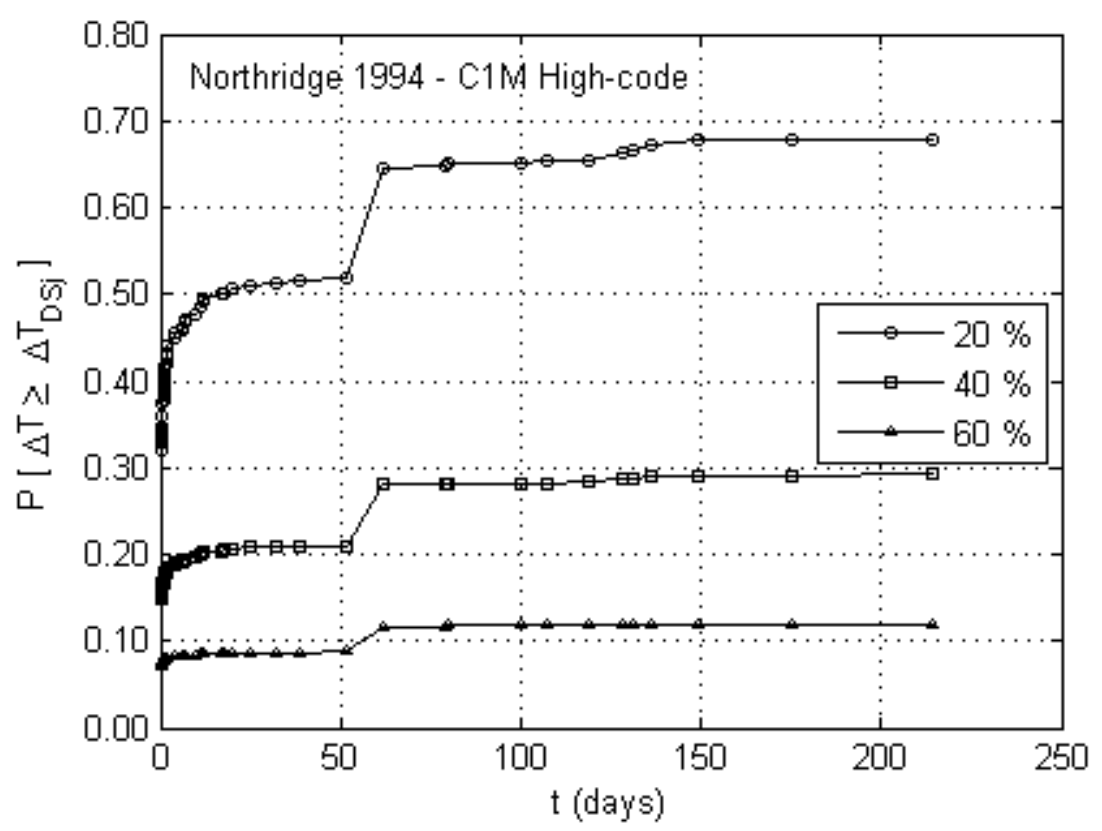

a)

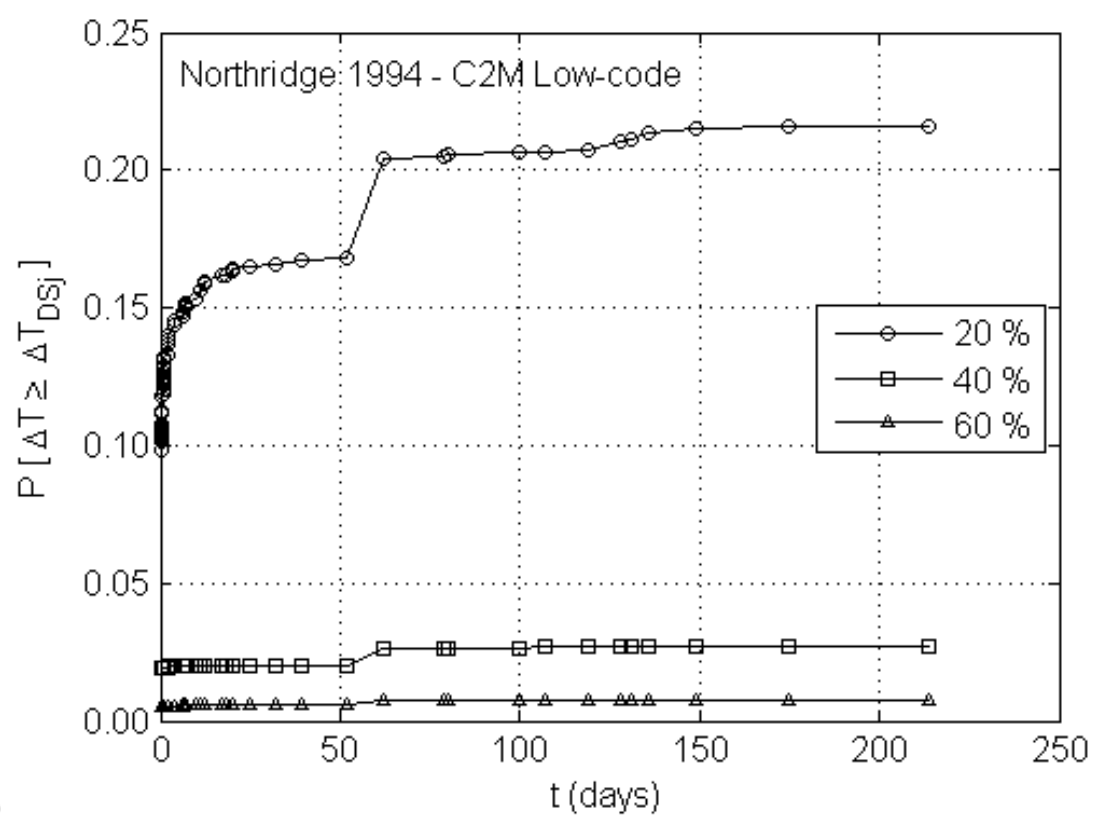

Figure 11: Probability exceedance of limit damage state thresholds in the form of period elongation $(\Delta T)$ in the case of the 1994 Northridge aftershock sequence for the C1M high-code (a) and the C2M low-code building (b).

The proposed calculation procedure can be performed for $\mathrm{RC}$ buildings with a structural system of moment resisting frames, shear walls, or dual irrelevant of the number of storeys, and for any series of seismic events, e.g. in order to estimate structural deterioration due to small magnitude earthquakes during a time period. Moreover, this method gives the stiffness degradation ratio of the structural elements of a building and therefore the location of seismic damage depending on the frequency content of the excitations and the dynamic characteristics of the building. This is considered an advantage over pushover analyses, during which the locations of the plastic hinges depend significantly on the load pattern.

Improvements upon the presented study may be achieved by accounting for the uncertainties in the prediction of the PGA, and by exploring alternative Intensity Measures and different 
types of time-histories as excitation of the numerical models. It is also worth taking into account infill walls and their possible irregularity in height, as well as possible shear and residual deformations of the structural elements.

\section{AKNOWLEDGEMENTS}

This study was carried out in the framework of the research programme "STREST" - Harmonized approach to stress tests for critical infrastructures against natural hazards (http://www.strest-eu.org) funded by the European Union's Seventh Framework Programme (FP7/2007-2013, Grant agreement No. 603389).

\section{REFERENCES}

[1] Comité Européen de Normalisation, Eurocode 8: Design of structures for earthquake resistance - Part 1: General rules, seismic actions and rules for buildings, EN 19981:2004:E, 2004.

[2] H. Ziar, Time variation of fragility curves for seismic vulnerability assessment of reinforced concrete structures, Research report, Université Joseph Fourier, 2014.

[3] K.D. Pitilakis, S.T. Karapetrou and S.D. Fotopoulou, Consideration of aging and SSI effects on seismic vulnerability assessment of RC buildings, Bulleting of Earthquake Engineering, 12, 1777-1803, 2014.

[4] M. Sanchez-Silva, G.-A. Klutke and D.V. Rosowsky, Life-cycle performance of structures subject to multiple deterioration mechanism, Structural Safety, 33, 206-217, 2011.

[5] I. Iervolino, M. Giorgio and E. Chioccarelli, Closed-form aftershock reliability of damage-cumulating elastic-perfectly-plastic systems, Earthquake Engineering and Structural Dynamics, 43, 613-625, 2014.

[6] G.D. Hatzigeorgiou and D.E. Beskos, Inelastic displacement ratios for SDOF structures subjected to repeated earthquakes, Engineering Structures, 31, 2744-2755, 2009.

[7] E. Miranda and J. Ruiz-Garcia, Influence of stiffness degradation on strength demands of structures built on soft soil sites, Engineering Structures, 24, 1271-1281, 2002.

[8] A. Masi and M. Vona, Experimental and numerical evaluation of the fundamental period of undamaged and damaged RC framed buildings, Bulletin of Earthquake Engineering, 8, 643-656, 2010.

[9] E.I. Katsanos, A.G. Sextos and A.S. Elnashai, Prediction of inelastic response periods of buildings based on intensity measures and analytical model parameters, Engineering Structures, 71, 161-177, 2014.

[10] E.I. Katsanos and A.G. Sextos, Inelastic spectra to predict period elongation of structures under earthquake loading, Earthquake Engineering and Structural Dynamics, published online, 2015.

[11] E. Vidal, M. Navarro, C. Aranda and T. Enomoto, Changes in dynamic characteristics of Lorca RC buildings from pre- and post-earthquake ambient vibration data, Bulletin of Earthquake Engineering, 12, 2095-2110, 2014.

[12] Conseil de L'Europe, G. Grünthal (ed), European Macroseismic Scale, Cahiers du Centre Européen de Géodynamique et de Séismologie, 15, 1998. 
[13] J. Régnier, C. Michel, E. Bertrand and P. Guéguen, Contribution of ambient vibration recordings (free-field and buildings) for post-seismic analysis : The case of the Mw 7.3 Martinique (French Lesser Antilles) earthquake, November 29, 2007, Soil Dynamics and Earthquake Engineering, 50, 162-167, 2013.

[14] P. Roux, P. Guéguen, L. Baillet and A. Hamze, Structural-change localization and monitoring through a perturbation-based inverse problem, The Journal of the Acoustical Society of America, 136, 2586-2597, 2014.

[15] A.J. Kappos, G. Panagopoulos, C. Panagiotopoulos and G. Penelis, A hybrid method for the vulnerability assessment of R/C and URM buildings, Bulletin of Earthquake Engineering, 4, 391-419, 2006.

[16] Earthquake Planning and Protection. EAK 2000 - Greek Antiseismic Code 2000, GG 2184/B/20-12-1999, Hellenic Republic, 2001. (in Greek)

[17] M. Fardis, E. Carvalho, A. Elnashai, E. Faccioli, P. Pinto and A. Plumier, Designer's guide to EN 1998-1 and EN 1998-5 Eurocode 8: Design of structures for earthquake resistance, Thomas Telford Publishing ,2005.

[18] G.G. Penelis and G.G. Penelis, Concrete buildings in seismic regions, CRC Press, 2014.

[19] A.J. Kappos, G.K. Panagopoulos, A.G. Sextos, V.K. Papanikolaou and K.C. Stylianidis, Development of comprehensive earthquake loss scenarios for a Greek and a Turkish city - structural aspects, Earthquakes and Structures, 1, 197-214, 2010.

[20] Federal Emergency Agency, HAZUS-MH 2.1 - Technical Manual - Earthquake Model, Department of Homeland Security, 2012.

[21] S. Mazzoni, F. McKenna, M.H. Scott and G. L. Fenves, Open System for Earthquake Engineering Simulation - user manual, Pacific Earthquake Engineering Research Center, University of California, Berkeley, CA, 2009.

[22] Earthquake Planning and Protection, Code for Interventions, GG 2187/B/05-09-2013, Hellenic Republic, 2013. (in Greek)

[23] J. Douglas, Ground-motion prediction equations 1964-2010, Pacific Earthquake Engineering Research Center - brgm, 2011.

[24] E. Delavaud, F. Cotton, S. Akkar, F. Scherbaum, L. Danciu, C. Beauval, S. Drouet, J. Douglas, R. Basili, M. A. Sandikkaya, M. Segou, E. Faccioli, N. Theodoulidis, Toward a ground-motion logic tree for probabilistic seismic hazard assessment in Europe, Journal of Seismology, 16, 451-473, 2012.

[25] Seismosoft, SeismoArtif, Version 2.1, Computer Program, Available at: seismosoft.com, Accessed: 02 February 2015, 2013.

[26] B. Halldorsson and A. S. Papageorgiou, Calibration of the Specific Barrier Model to earthquakes of different tectonic regions, Bulletin of the Seismological Society of America, 95, 1276-1300, 2005.

[27] A. Zacharenaki., M. Fragiadakis, D. Assimaki and M. Papadrakakis, Bias assessment in in Incremental Dynamic Analysis due to record scaling, Soil Dynamics and Earthquake Engineering, 67, 158-168, 2014. 
[28] D. Vamvatsikos, C.A. Cornell, Developing efficient scalar and vector intensity measures for IDA capacity estimation by incorporating elastic spectral shape information, Earthquake Engineering and Structural Dynamics, 34, 1573-1600, 2005.

[29] A.J. Kappos, Seismic vulnerability and loss assessment for buildings in Greece, P. Guéguen ed., Seismic Vulnerability of Structures, ISTE Ltd and John Wiley \& Sons Inc, 2013.

[30] M. Perrault, P. Guéguen, A. Aldea and S. Demetriu, Using experimental data to reduce the single-building sigma of fragility curves: case study of the BRD tower in Bucharest, Romania, Earthquake Engineering and Engineering Vibration, 12, 643-658, 2013.

[31] B.C. Papazachos and P.G. Carydis, The time, magnitude and space distributions of the 1978 Thessaloniki seismic sequence, The Thessaloniki, Northern Greece, earthquake of June 20 1978, and its seismic sequence, Technical Chamber of Greece - Section of Central Macedonia, 1983.

[32] E. Hauksson, L.M. Jones and K. Hutton, The 1994 Northridge earthquake sequence in California: seismological and tectonic aspects, Journal of Geophysical Research, 100, 12,335-12,355, 1995.

[33] H.K. Thio and H. Kanamori, Source complexity of the 1994 Northridge earthquake and its relation to aftershock mechanisms, Bulletin of the Seismological Society of America, 86, S84-S92, 1996.

[34] B.C. Papazachos, P.E. Comninakis, G.F. Karakaisis, B.G. Karakostas, Ch.A. Papaioannou, C.B. Papazachos and E.M. Scordilis, A catalogue of earthquakes in Greece and surrounding area for the period 550BC-1999, Publ. Geophys. Laboratory, University of Thessaloniki, 2000.

[35] B.C. Papazachos, P.E. Comninakis, E.M. Scordilis, G.F. Karakaisis and C.B. Papazachos, A catalogue of earthquakes in the Mediterranean and surrounding area for the period 1901 - 2010, Publ. Geophys. Laboratory, University of Thessaloniki, 2010.

[36] B.C. Papazachos, V.G. Karakostas, A.A. Kiratzi, B.N. Margaris, C.B. Papazachos and E.M. Scordilis, Uncertainties in the estimation of earthquake magnitudes in Greece, Journal of Seismology, 6, 557-570, 2002.

[37] S. Akkar and J.J Bommer, Empirical equations for the prediction of PGA, PGV and spectral accelerations in Europe, the Mediterranean region, and the Middle East, Seismological Research Letter, 81, 195-206. 2010.

[38] A.A. Scarlatoudis, C.B. Papazachos, B.N. Margaris, N. Theodoulidids, C. Papaioannou, I. Kalogeras, E.M. Scordilis and V. Karakostas, Empirical peak ground-motion predictive relations for shallow earthquakes in Greece, Bulletin of the Seismological Society of America, 93, 2591-2603, 2003.

[39] M. Causse, A. Laurendeau, M. Perrault, J. Douglas, L.F. Bonilla and P. Guéguen, Eurocode 8-compatible synthetic time-series as input to dynamic analysis, Bulletin of Earthquake Engineering, 12, 755-768, 2014. 